\title{
PARASTREMMATIC DWARFISM
}

\author{
Frank Horan, London, England, and Peter Beighton, Cape Town, Solth Africa \\ From the Department of Human Genetics, Medical School, University of Cape Town
}

A girl aged ten, of Cape Coloured stock, with typical features of parastremmatic dwarfism has been investigated. The clinical manifestations included disproportionate dwarfism, limb deformity, a short stiff neck, and marked thoracic kyphosis. The radiographic changes were dramatic, the skeleton having a "flocky" appearance due to patches of radiolucency in an irregular lattice of sclerosis. The metaphyses and epiphyses of the long bones were grossly expanded, and the vertebrae were flattened and distorted. The clinical and radiographic features of five other previously reported individuals with parastremmatic dwarfism were very similar to those of our patient. The differential diagnosis of this condition includes metatrophic dwarfism, diatrophic dwarfism and the spondylo-epiphysial dysplasias. However, the unique "flocky" radiographic appearance of the bones permits diagnostic precision. There is some evidence to indicate that parastremmatic dwarfism might be transmitted as an autosomal dominant, although this is by no means certain. The fact that our patient had seven normal siblings and unaffected parents would be compatible with autosomal recessive inheritance.

The term "parastremmatic dwarfism", derived from the Greek "parastremma" meaning "distorted limb", was applied by Langer, Petersen and Spranger (1970) to a condition characterised by severe dwarfism, marked kyphoscoliosis with increased antero-posterior diameter of the chest, bizarre and frequently asymmetrical deformities of the lower extremities and multiple joint contractures. Abnormalities are manifest at birth or in early infancy.

The purpose of this paper is to describe a severely affected girl, to review the clinical and radiographic features and to discuss the orthopaedic significance of the syndrome.

\section{CASE REPORT}

The patient, the fifth of eight siblings of Cape Coloured stock, was born in January 1965. Her parents and their other seven children are of normal stature and show no evidence of skeletal abnormality. No other member of the kindred is affected, and there is no known consanguinity.

The patient attended the Groote Schuur Hospital, Cape Town, in May 1970, when she was five years of age. She had a marked thoracic kyphosis and short limbs, with prominent joints. She was incontinent of urine and faeces and had a sacral bed-sore. She had never walked but she had talked from the age of one and was of normal intelligence. Her mother stated that the deformities were obvious at birth and that at that time she was "just a small version of what she is now". Long tract signs suggestive of spinal cord compression at the level of the thoraco-lumbar junction were present. However, no abnormality could be demonstrated by myelography.

The patient was re-examined in November 1974. Her general health had remained good apart from recurrent chest infections and persistent incontinence of faeces and urine. She was found to be a shy child, 90 centimetres in height. She had brachycephaly and a high forehead with a prominent lower

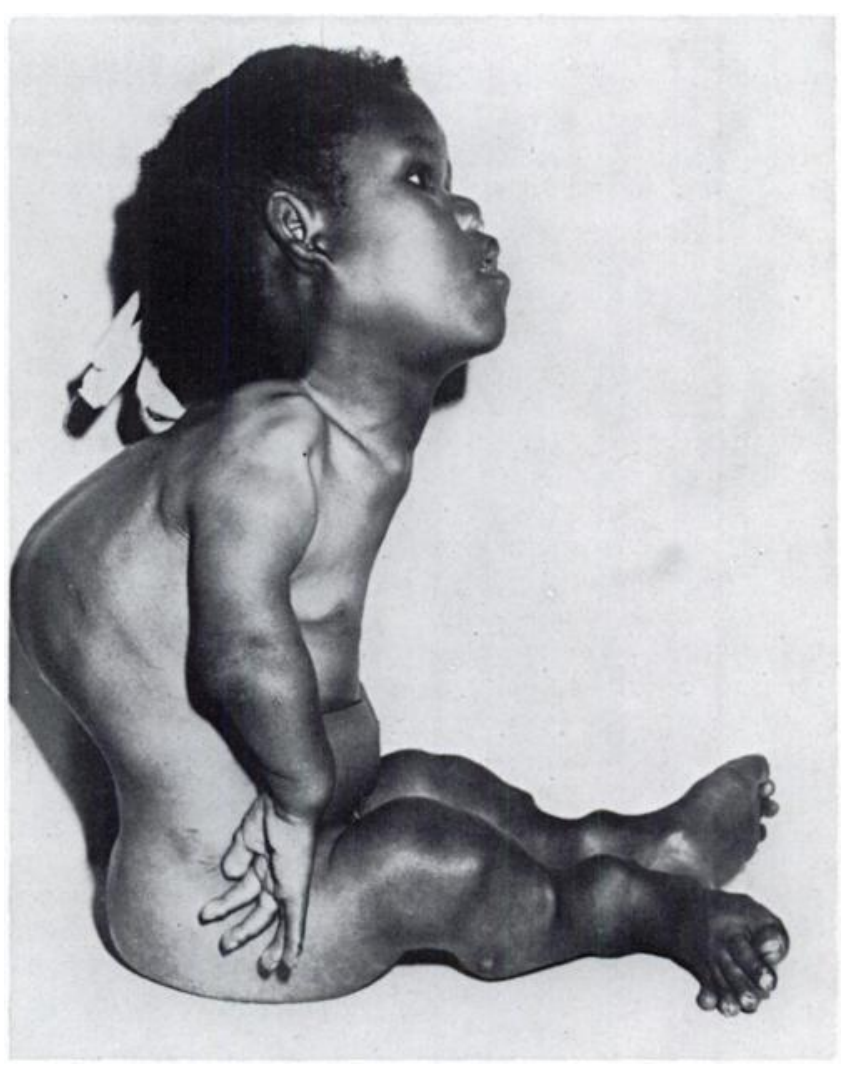

FIG. 1

The patient at the age of 5 years. Marked kyphosis, fixed deformity of the neck, and limb deformities are present.

jaw and a flat nasal bridge. The neck was stiff and held in extension and lateral tilt. There was a severe fixed thoracic kyphosis with moderate scoliosis (Fig. 1). She could not stand and her usual position was either lying flat or sitting propped in a small chair. 


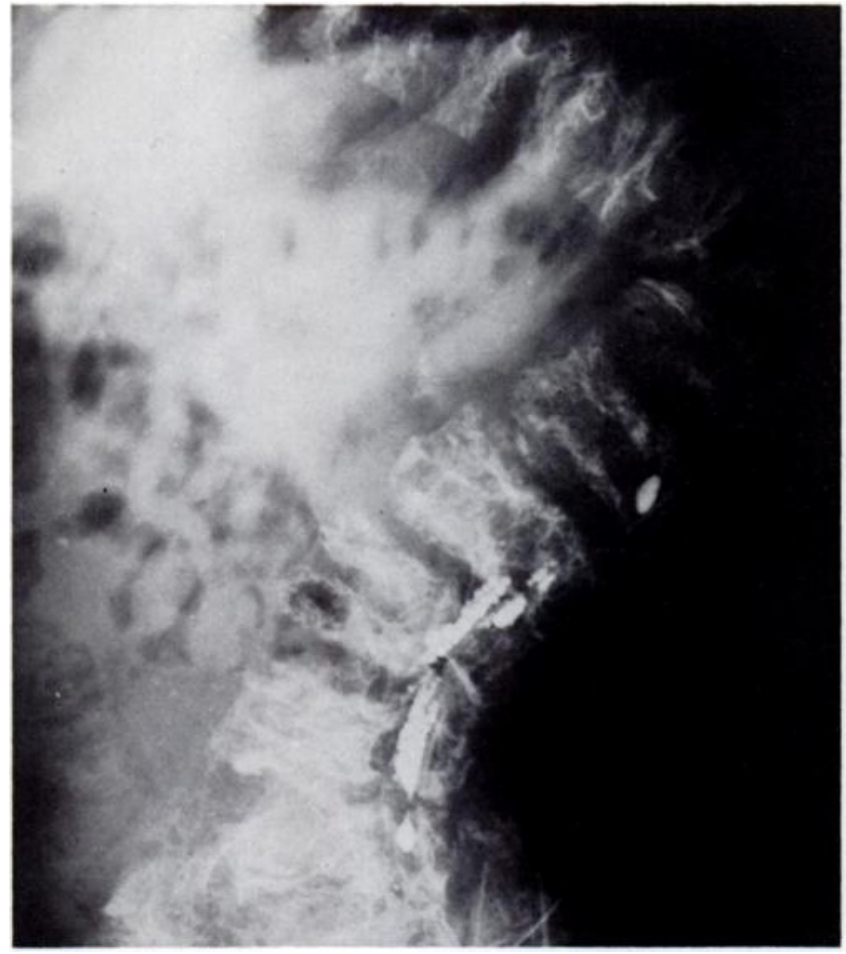

FiG. 2

Lateral view of the lower thoracic and upper lumbar spine at the age of 9 years showing kyphosis and the homogeneous appearance of the bone.

The hips were mobile but had a fixed flexion deformity of 30 degrees and could be flexed to 90 degrees. The knees showed marked enlargement of the metaphysio-epiphysial regions, with bilateral varus deformity, and flexion contractures of $\mathbf{4 5}$ degrees. The ankles and feet were stiff but without significant deformity.

The shoulders could be passively abducted to 90 degrees, with considerable limitation of rotation. The elbows bent from 45 to 90 degrees. Only a few degrees of pronation and supination were possible in the forearms. The wrists were markedly lax, permitting 90 degrees of dorsiflexion and 90 degrees of palmar flexion.

The thumbs were normal. The metacarpo-phalangeal joints in both hands were hypermobile and allowed 100 degrees of passive extension of the fingers. The proximal interphalangeal joints of the ulnar three fingers in both hands were hypermobile and 45 degrees of hyperextension could be obtained. The proximal interphalangeal joints of the index fingers were stiff, with very little movement, while in the distal interphalangeal joints of all fingers only a few degrees of flexion was possible, with no extension. The hands were floppy.

The knee and ankle reflexes were brisk, with extensor plantar responses. Upper limb reflexes were normal.

Radiographic features-Radiographs obtained at the ages of five and nine years were available for review. In the early radiographs the bones were markedly porotic, while at nine increased mineralisation had occurred. The areas of growth plate ossification were markedly expanded, with gross irregularity of endochondral bone formation. These sites showed patches of radiolucency in an irregular lattice-like web of sclerosis. The adjective "flocky", previously used by Langer et al. (1970) accurately describes this appearance. In the spine gross kyphoscoliosis and marked platyspondyly were present. The bone mass appeared homogeneous and the disc spaces or vertebral outlines could be distinguished only with difficulty (Fig. 2).

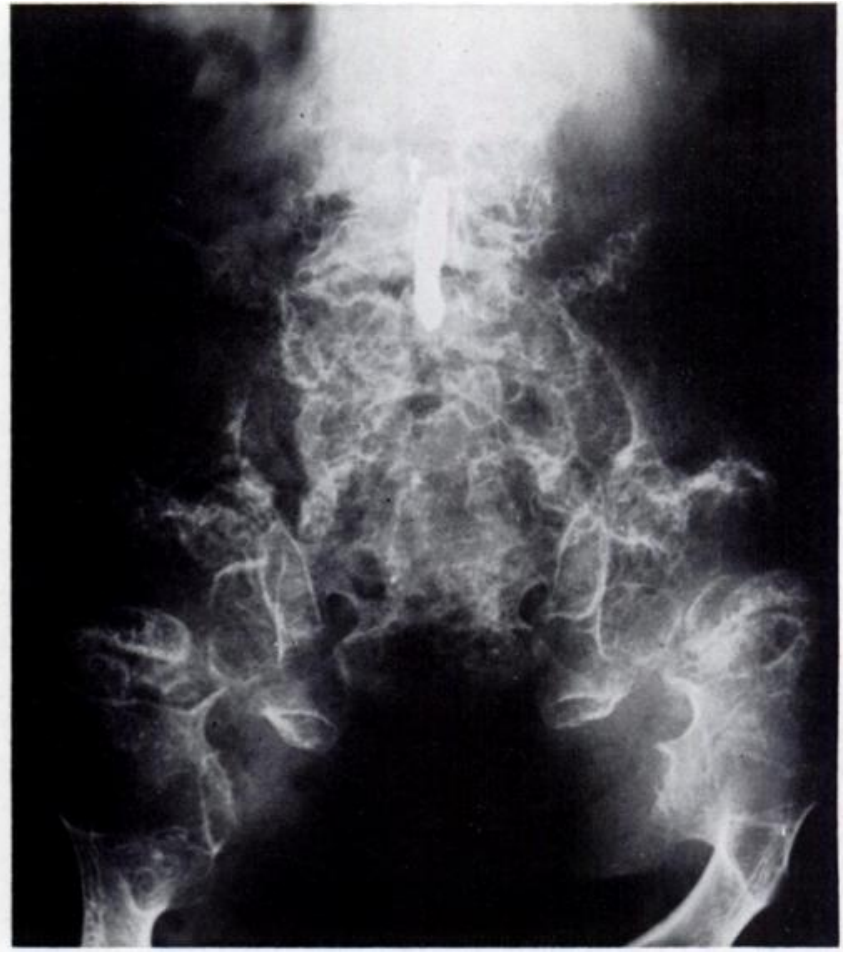

Fig. 3

Antero-posterior view of the pelvis and hips at the age of 9 years. The dysplastic acetabula, subluxated femoral heads, broad femoral necks and developing capital epiphyses are evident.

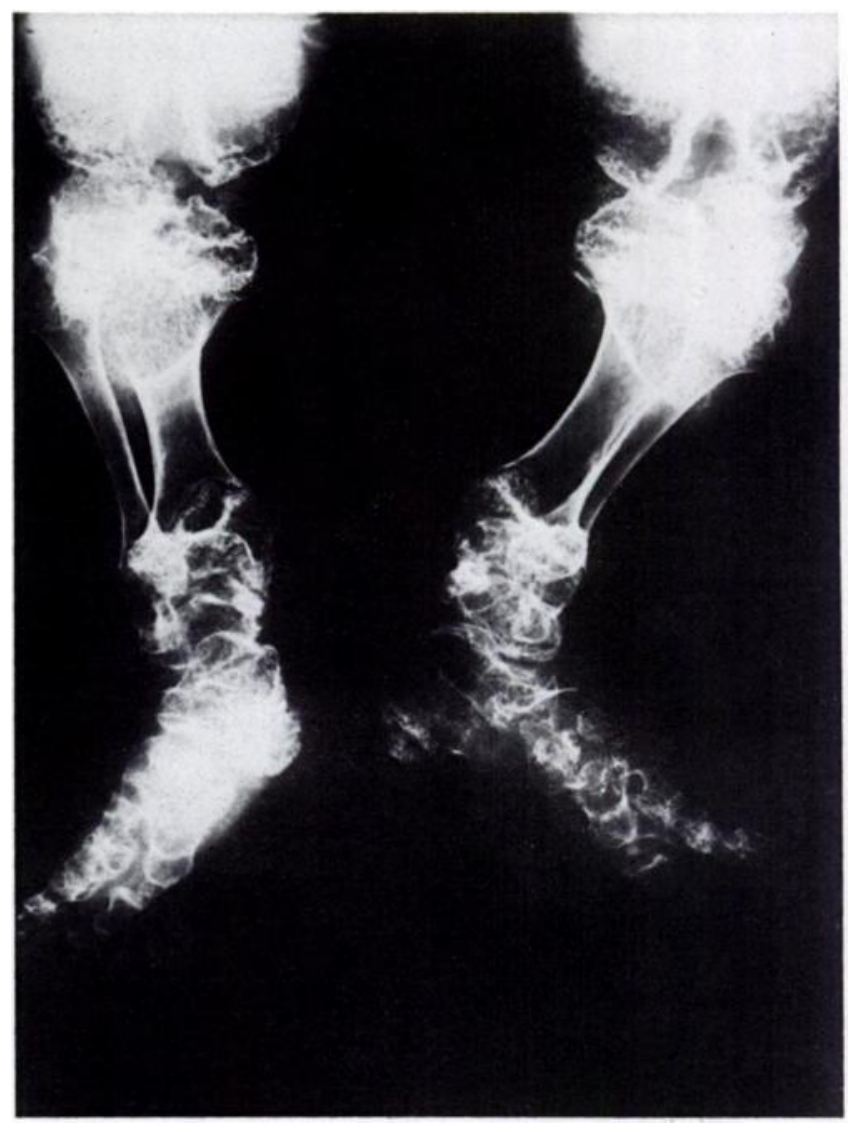

FiG. 4

Antero-posterior views of the lower limbs at the age of 9 years. The metaphyses and epiphyses are greatly enlarged and show the "flocky" appearance of the bone. 
In earlier films the iliac wings were prominent in relation to the underdeveloped acetabular regions. The later radiographs showed improved development of the acetabula, although they had remained irregular and dysplastic (Fig. 3). The enlarged femoral heads were subluxated but the capital epiphyses were reasonably well developed. The femoral necks

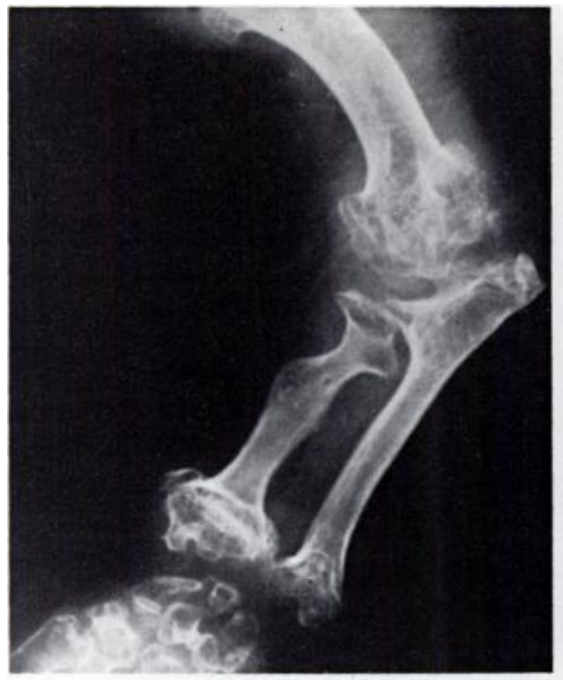

FIG. 5 radiographic changes were compatible with the diagnosis of parastremmatic dwarfism. Langer, Spranger and Petersen (1970) gave details of three further patients and drew attention to a father and daughter with similar stigmata who had been described by Rask (1963). The

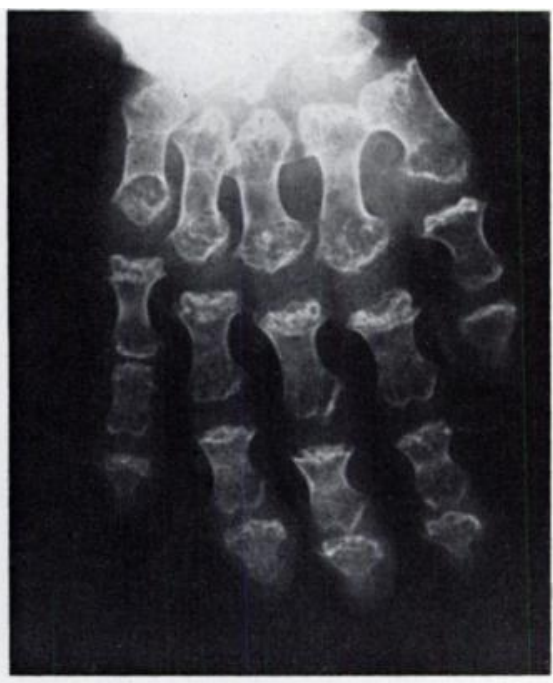

Fig. 6

Figure 5-Radiograph of the right arm. Note the foreshortening of the tubular bones, with flocky expansion of the bone ends. Figure 6-Distortion of the small bones of the hand.

were almost vertical, being broad and long in relation to the shafts.

The long bones (Figs. 4 to 6) showed similar changes which were most marked in the lower limbs. The foreshortened shafts flared into greatly enlarged metaphyses and epiphyses, particularly at the distal ends of the femora. The epiphysial lines were just distinguishable in the confluent bony mass.

\section{REVIEW OF THE CLINICAL FEATURES OF PARASTREMMATIC DWARFISM}

Apert, Liège and Dennis (1934) reported the case of a twelve-year-old girl in whom the clinical features and main characteristics recorded in these case descriptions, together with those of our patient, are shown in Table I. Joint stiffness and spinal deformity were the presenting features at birth in our patient and in those of Langer et al. (1970). Walking was generally delayed and all patients had an abnormal gait due to deformity of the hip and knee. The reported patients were able to walk reasonably well, in contrast to our patient, who had never walked. All affected individuals were severely dwarfed, the loss of stature being due to a combination of shortness of the tubular bones, kyphoscoliosis and platyspondyly.

TABLE I

Clinical Features of Patients with Parastremmatic Dwarfism

\begin{tabular}{|c|c|c|c|c|c|c|c|}
\hline \multirow{2}{*}{$\begin{array}{l}\text { Author } \\
\text { Patient }\end{array}$} & \multirow{2}{*}{..} & \multicolumn{3}{|c|}{ Langer et al. (1970) } & \multicolumn{2}{|c|}{ Rask (1963) } & \multirow{2}{*}{$\frac{\text { Present report }}{\text { S.v.B. }}$} \\
\hline & & 1 & 2 & 3 & Daughter & Father & \\
\hline Age (years) & . & 13 & 10 & 10 & 15 & 52 & 9 \\
\hline Sex & . & Female & Female & Female & Female & Male & Female \\
\hline Height (centimetres) & . & 99 & 100 & 91 & 86 & 109 & 90 \\
\hline Thoraco-lumbar kypho & coliosis & + & + & + & + & + & + \\
\hline Thoracic deformity & . & + & + & + & + & + & + \\
\hline Short neck & . & + & + & + & + & + & $\therefore$ \\
\hline Stiffness of leg joints & . & + & + & + & + & + & + \\
\hline Knobbly joints & . & + & + & + & + & + & $\hookrightarrow$ \\
\hline Upper limb deformity & . & Mild & Mild & Mild & Mild & Mild & Mild \\
\hline Lower limb deformity & . & Severe & Moderate & Moderate & Moderate & Severe & Moderate \\
\hline Stubby hands & . & + & $?$ & + & + & - & $\therefore$ \\
\hline Skull configuration & . & Abnormal & $?$ & Normal & Normal & Normal & Abnormal \\
\hline
\end{tabular}


A short stiff neck with an increase in the antero-posterior diameter of the thorax and sternal deformity was a consistent feature. The knobbly joints of the long bones were universal, and joint stiffness, particularly in the knees, hips and elbows, was present in all patients.

Differential diagnosis-The differential diagnosis has been fully reviewed by Langer et al. (1970) and by Spranger, Langer and Wiedemann (1974). The association of kyphoscoliosis with platyspondyly, metaphysial abnormality and epiphysial changes may be encountered in other conditions such as metatropic dwarfism, diastrophic dwarfism and the spondylo-metaphysial dysplasias. However, the unique radiographic appearance of the "flocky bones" distinguishes parastremmatic dwarfism.

\section{DISCUSSION}

Histological reports of biopsy specimens quoted in the papers of Rask (1963) and Langer et al. (1970) suggest that the basic defect lies in a lack of columnisation of cartilage cells in the growth plate and in failure of normal conversion of these cartilage columns into bone. This hypothesis is in keeping with the radiographic appearance of lucent areas interspersed with lattice-like trabecular formation. This failure in endochondral bone formation results in a piling up of abnormal osseous tissue adjacent to the growth plate and gross expansion of the epiphysial and metaphysial areas. As a consequence, remodelling and normal longitudinal growth fail to occur.

Parastremmatic dwarfism is probably a genetic disorder, and the occurrence of the condition in an affected father and daughter (Rask 1963) is evidence for autosomal dominant inheritance. However, the situation in this kindred is not clear cut, as although the father was considered to have parastremmatic dwarfism, the mother had osteogenesis imperfecta, and the daughter was thought to have inherited both disorders. It is possible that the condition in this kindred was something other than parastremmatic dwarfism.

As the parents of our patient were both unaffected, she may represent a new mutation of the abnormal gene. However, in view of the diagnostic confusion, there is still considerable doubt as to the precise mode of genetic transmission, and autosomal recessive inheritance is entirely compatible with our patient's family situation.

We are grateful to our orthopaedic colleagues Professor C. L. Allen and Mr Brian Jones for their permission for us to investigate this patient, to Mr R. A. Du Ménaud for the illustrations and to Mrs G. Beighton for preparing the manuscript. We acknowledge with gratitude the assistance of our good friend Dr Jurgen Spranger, who first reached the correct diagnosis. fund.

This study was supported by grants from the South African Medical Research Council and the University of Cape Town staff research

\section{REFERENCES}

Apert, E., Liège, R., and Denet, J. (1934) Dystrophie ostéo-articulaire grave chez une fille de 12 ans. Bulletins de la Société de pédiatrie de Paris, 32, 577-585.

Langer, L. O., Petersen, D., and Spranger, J. (1970) An unusual bone dysplasia: parastremmatic dwarfism. American Journal of Roentgenology, Radium Therapy and Nuclear Medicine, 110, 550-560.

Rask, M. R. (1963) Morquio-Brailsford osteochondrodystrophy and osteogenesis imperfecta. Journal of Bone and Joint Surgery, 45-A, $561-570$.

Spranger, J. W., Langer, L. O., Jun., and Wiedemann, H.-R. (1974) Parastremmatic dwarfism. In Bone Dysplasias: An Atlas of Constitutional Disorders of Skeletal Development, pp. 131-133. Philadelphia and Toronto: W. B. Saunders Company. 